\title{
DE BEVELHEBBER EENER RETOURVLOOT.
}

W anneer de Retourvloot te Batavia gereed gemaakt werd om naar het vaderland te vertrekken, werd daarover een hoofd gesteld, die naarmate van den rang door hem bekleed, den titel droeg van Admiraal of Commandeur, de daarop volgende kreeg dien van Vice-Admiraal of Vice-Commandeur en Schout-bijNacht.

Aan den Admiraal of Commandeur werd eene instructie ter hand gesteld, waarna hij zich had te gedragen; onder de verschillende bepalingen daarin voorkomende, behoorden de volgende:

1. Na de gedane monstering door den Waterfiscaal, zoo spoedig mogelijk te trachten buiten Straat Sunda te komen.

De monstering geschiedde om te zien of er onder de equipagiën der verschillende schepen, zich personen onthielden die niet geregtigd waren naar het vaderland terug te keeren; zoo mede na te gaan of de verschillende bepalingen ten opzigte der vertrekkende schepen in allen deele waren nagekomen.

2. Het maken van een seinbrief; waartoe behoorde:

a. het verdeelen der vloot in drie eskaders,

$b$. het bepalen en regelen der koers,

c. de order waarin de vloot zoude zeilen,

$d$. order op het voeren der vuren bij nacht enz.

3. Buiten het Prinsen eiland en in volle zee gekomen, bij elkander trachten te blijven en zoo spoedig doenlijk de Kaap te bereiken.

4. Altijd op hoede en slagvaardig te zijn, al was men met de verschillende Europesche natiën in vrede.

5. Schepen dic de Kaap noch de Saldanha-baai konden bezei- 
len, en de Stat in vrede met de Engelschen zijnde, mogten St. Helena aandoen.

6. Gebruik maken van de instructie op het aandoen van de Kaap of Saldanha-baai.

7. Tot op eene zekere tijd aan de Kaap op de Ceilonsche schepen wachten.

8. Bij vertrek van de Kaap en zoo er schepen van de vloot waren afgedwaald, het eiland St. Helena bij dag aan te loopen om te zien of die daar ten anker lagen.

9. Buiten Ierland en Schotland om te loopen.

10. Te overleggen of tusschen Fairhill en Hitland of tusschen Hitland en de eilanden van Fero doorgeloopen zoude worden.

11. Wanneer de vloot door het kanaal liep, alsdan de vlaggen innemen en alleen een wimpel van de toppen te voeren, om alle moeite met de Engelsehen voor te komen.

12. Bij het ontmoeten van de op de vloot kruisende oorlogschepen, te observeren wat ten dien aanzien bepaald was ${ }^{1}$.

13. Hoedanig de Breede Raad zamengesteld was; goede order en tucht in acht te nemen en regt en justitie te doen nakomen enz.

Wanneer het oogenblik van vertrek gekomen was, werd hem doorgaans uitgeleide gedaan door eenige leden der Hooge Regering, die hem aan boord van het vlaggeschip aan de equipage voorstelden, en hem zijne commissie overhandigden. Bij aankomst in een van de vaderlandsche havens begaf zich de Admiraal naar Amsterdam - soms werd hij met het compagnies jacht afgehaald - en deed in de vergadering van Bewindhebberen verslag van zijne reize, waarna hij bedankt werd, en hem ter gedachtenis eene vereering gedaan, bestaande in een gouden keten en medaille ter waarde van 500 tot 1000 gulden, naar den rang dien hij bekleed had. Was de Admiraal een oud-Gouverneur-Generaal, zoo als onder anderen Johan van Hoorn, die in het jaar 1710 , de retourvloot kommandeerde, dan was de waarde dier keten en medaille hooger, namelijk vijftien honderd gulden. Maar niet alleen moest door den Bevelhebber der retourvloot verslag van zijne reize in de vergade-

1 Zie Particuliere seinen, bepaald door den Kapitein Nicolaas Cau, bij het kruisen op de Oost-Indische Retourschepen in 1724. Verhandelingen

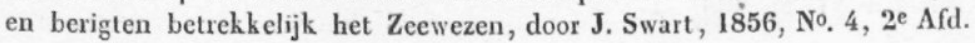


ring der Zeventienen worden gedaan, ook in de vergadering van Hunne Hoog Mogenden werd dit vereischt.

Dit geschiedde op de volgende wijze; er werd eene Commissie zamengesteld uit eenige Bewindhebberen en de twee Advocaten der Compagnie, om den Bevelhebber aan H. H. M. voor te stellen.

Deze Commissie begaf zich tot dat einde naar 's Hage; den volgenden dag na hunne aankomst bragt de President en de oudste Advocaat eene visite aan den President van H. H. M. zoomede aan den Griffier; deze bragten het verlangen der Commissie in de vergadering, wanneer doorgaans den volgenden dag voor de receptie werd bepaald.

'S anderen daags 'smorgens tegen elf ure, begaf zich de Commissie in drie rijtuigen gezeten naar de vergadering.

In het eerste rijtuig namen plaats, twee Bewindhebberen en de eerste Advocaat.

In het tweede twee Bewindhebberen.

In het derde twee Bewindhebberen en de Bevelhebber der retourvloot.

De Commissie werd gebragt in de Trèves kamer en vervolgens in de vergaderzaal van H. H. M. waar ieder op de voor hem bestemde stoel plaats nam, met uitzondering van den Bevelhebber, die naast den jongsten Advocaat bleef staan. De eerste Advocaat deed zittende de aanspraak, waarbij in de Introductie gezegd werd, dat, vermits het rapport van den Bevelhebber, hetgeen hij de eer had aan H. H. M. aan te bieden, slechts behelsde zaken, die op de reis waren voorgevallen, hij Advocaat aan H. H. M. zal onder het oog brengen een kort detail van de Indische zaken en den toestand der verschillende kantoren; waarmede hij dan van Amboina af tot Batavia ingesloten, en in die orde als bij het Haagsch verbaal bepaald werd dat rapport deed hetgeen doorgaans een half uur duurde.

Daarna reed men in dezelfde orde weder naar het Logement, ${ }^{1}$ waar 's middags een maaltijd werd gehouden van circa twintig personen. De Toasten werden daarbij niet vergeten, zoo als:

1 Dit Logement bij Resolutie van de Bewindhebb. in hunne vergadering van den 7 den Maart 1690, aangekocht van Mevrouw Van Beuningen,

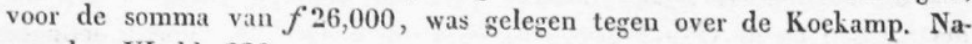
vorscher VI. bl. 336. 
Het welvaren van de Republiek.

H. H. Mog. de gevers van het octroy.

Orange \&. \&. \&.

Den Bevelhebber werd een groote pokaal met wijn gepresenteerd; de President feliciteerde hem met een klein pokaaltje, met het behouden overbrengen van de retourvloot, en werd hij voor zijne diensten des wegens aan de Compe. betoond, bedankt.

Wanneer alle de gasten dit mede hadden gedaan, dan stond hij op, bedankte voor de hem angedane eer en dronk op het welvaren van de Compe. den grooten beker uit.

Het zal ongetwijfeld de belangstelling van velen opwekken om, door een voorbeeld uit de geschiedenis, kennis te nemen van de ceremoniën, bij deze gelegenheid geobserveerd, en van zulk een kort detail van de Indische zaken en van den toestand der verschillende kantoren. Een geschikt voorbeeld scheen dat van den Commàndeur der Retourvloot, den Heer Roelof Blok, die van 1756 tot 1760 de waardigheid van Gouverneur en Direkteur ter Zuid-Kust van Celebes bekleedde ${ }^{1}$; hetgeen daarom hier volgt:

DE COMMANDEUR DER RETOURVLOOT AAN HUNNE HOOG MOGENDE GEPRESENTEERD DEN $20^{\text {TRE }}$ APRIL 1763.

Den 18den April 1763. Maandag avond in 's Hage gearriveerd zịnde, zoo zijn dingsdag morgen de Heeren De Wilhem en Van Ouwerkerk benevens den Advocaat Van Son, ten 10 uren gereden naar den Heer Griffier Fagel, en vervolgens naar het huis van den Heer President van Hunne Hoog Mogende den Heer Bergsma - om aldaar kennis te geven van derzelver arrivement en het oogmerk waartoe; 's middags door den Heer President laten weten, dat H. H. Mog. op morgen ten $11 \frac{1}{2}$ uren de Commissie zoude verwagten.

Den 20sten April 1763, den Commandeur gepresenteerd.

1 Roelof Blok is ook vermaard geworden door zijn beknopte geschiedenis van het Makassaarsche Celebes en onderhoorigheden, welke is opgenomen in het Tijdschrift voor Nederlandsch Indië, jaarg. 1848, eerste deel, bladz. 3-77. Hij kwam in 1746 in Indië als Kapitein ter zee, met het schip de Waakzaamheid, voor de Kamer Enkhuizen, waar hij ook geboren werd. 


\section{INTRODUCTIE.}

De jongste retourvloot der Oost-Indische Maatschappij, behouden in de havenen dezer landen gearriveerd zijnde, nemen Bewindhebberen de vrijmoedigheid, van aan H. H. Mog. te presenteren den Oud-Gouverneur van Macassar, Roelof Blok, onder wiens Commando en vlag gemelde vloot dat gelukkig retour heeft mogen erlangen.

Bewindhebberen H. Mog. Heeren doen zulks met te meer vrijmoedigheid, omdat zij in den persoon van dezen Commandeur, aan Uw Hoog Mog. voordragen mogen één van Compe. gewezen dienaren, die gedurende een lange reeks van jaren, in verscheidene opdragten en emploijen, aan de Maatschappij bewezen hebbende groote en menigvuldige diensten, is gerepatrieert met dat honorabele getuigenis van Generaal en Raden, van allezins waardig te vezen, gelouangeert en andere ten voorbeelde van een trouwhartige beijvering in 's Compe. dienst voorgesteld te worden.

Generaal en Raden meenende dat dit loffelijk getuigenis alleen niet voldoende was, maar dat - om hunne eigen woorden te gebruiken - 'smans brave hoedanigheden en de aan de Compagnie bewezene diensten, een gedistingueerder blijk van hun genoegen meriteerde, hebben aan het opgedragene commando gehegt die rang, qualiteit en dat honneur als een Lid van de Hooge Tafel alleen bij zijn retour gegeven wordt; en vertrouwen dat Bewindhebberen die gemaakte schikkingen om gealligeerde redenen wel zouden gelieven te agreëren.

Gelijk Bewindhebberen die schikkingen niet alleen hebben geagreërt, maar van Hare zijde medegetoond, hoe aangenaam het hun is, gelegenheid te mogen hebben om de trouwen dienst Harer dienaren te mogen erkennen; daar de Compe. echter klagende blijft, dat de zucht voor vaderland en vrienden Haar heeft ontrukt, een dienaar van wiens getrouwheid zij nog veele vruchten zoude kunnen hebben percepieren.

Dit vooraf gepermitteerd zijnde omtrend de persoon zelve, die eerbiedig verzoekt zich te mogen refereren aan zijn rapport inscriptis wegens het voorgevallene op de reis, zoo voegen Bewindhebberen hierbij dat de vloot, die in den jare 1762 is geretourneert, bestaan heeft in een aantal van vijf en twintig schepen, had aangebragt een inkoopsbedragen van meer dan drie en 'tachtig tonnen gouds. 
En geconsidereert dat uw H. Mog. deze gunstige audiëntie aan Bewindhebberen wel hebben gelieven te permitteren, om te erlangen een beknopt tafereel van de toestand der Indische zaken, zoo zij het Bewindhebberen gepermitteert kortelijk onder het oog van Uw Hoog Mogende te brengen, dat

1. Amboina heeft uitgeleverd een nagelgewas zonder voorbeeld, als bestaan hebbende in meer dan twee millioenen ponden. De ondervinding geleert hebbende, dat de overmatige gewasschen doorgaans van een zeer gering gevolgd worden, zoo gaat de calculative bepoting voor de volgende inzaam niet verder dan tot 52650 ponden. Hoezeer de nagelboomen bij continuatie gehouden worden, op een aantal van bijna zes maal honderd duizend stuks. Welkers getal noodzakelijk is, omdat de nagelcultuur in Ambon alleen werd aangekweekt, met extirpatie van dien alom in de Molukken, alwaar Compagnies Etablissementen jaarlijks zware kosten na zich slepen, gelijk dit Gouvernement daarvan getuigenis draagt ter montant van bijna twee ton jaarlijks.

2. Banda. Heeft uitgeleverd 445685 ponden notenmuscaten en 1300 sokkels foelij, en heeft meer lasten dan winsten gehad 157000 gulden.

3. Ternate. De regte teelplaats voor de Oostersche specerijen, verschaft de meeste zorg dat dezelve hier uitgevoerd worden, waarvoor de Maatschappij aan de Vorsten des Lands jaarlijks 35000 gulden betaald voor recognitie penningen.

De extirpatie was hier naar genoegen verrigt, en was hier aan stofgoud ingezameld 197 mark.

4. Makasser niet ten onregte genoemd de sleutel van de Oostersche provinciën, is in comparatie van vroegere dagen van zeer favorabelen aanschouw, want daar dit gouvernement een halve eeuw lang is geweest een jaarlijksche lastpost van bijna 150,000 gulden, is hetzelve onder de bestiering en directie van den Gouverneur Blok, gebragt tot een lastpost van onder de 40,000 gulden, op welken voet de tegenwoordigen Gouverneur Sinkelaar alle zijne vermogens aanwend, hetzelve te behouden.

De vertieningen waren in de Zuider en Noorder provinciën vrij favorabel uitgevallen, en worden de Gouverneurs zoo veel mogelijk daartoe gehouden, dat zij die vertieningen in persoon bijwoonen, tot voorkoming van knevelarijen waaraan de Inlander anderzins veel bloot gesteld is.

De indigo- en pepercultuur wil door de gansche Molukkes 
niet voortgroeijen, als waartoe het klimaat en de grond niet gedisponeerd schijnen, wordende de vorsten en de landman anderzins door alle engagable middelen daartoe geëngageerd.

5. Banjermassing, op het diamantrijke Borneo gelegen, is ten dien opzigte zeer schraal voor de Maatschappij; hoezeer de Residenten die voor zich zelve genoegzaam weten te bekomen.

De Maatschappij is overgegaan, om derzelver overvoer naar Nederland aan hare dienaren te permitteren, onder betaling van één percent recognitie of vrachtpenningen.

De Maatschappij heeft geen het minste effect van die permissie en blijft bij continuatie destituut van de gerequireerde soorten, quantiteiten en qualiteiten; het zij dat men penetreert dat de overvoer, de overvoerders tot schande zoude moeten verstrekken en men verbergen wil zijn wettig verkregen rijkdom of eerlooze Hoofden bezit.

De peper inzaam moet dan alhier wezen het groote doelwit en dezelve heeft jongst bestaan in een millioen ponden.

6. Timor. Aldaar regeert een groote zucht onder de bedienden, om voor Compagnies rekening, zekere goudgravinge te entameren, zoo als men daarmede ook een aanvang had gemaakt. Doch de ondervinding geleerd hebbende, wat een aanklevende kracht het Indische goud bij zoodanig graven heeft, en hoe weinig daarvan aan de Maatschappij komt, zoo heeft men dat werk gestuit en op zekere conditien voor den Inlander gelaten, die daarvan echter niet meer dan $7 \frac{3}{8}$ mark hebben gefourneerd.

De Maatschappij zoude te vergeefsch haar bestaan in goudrijke mijnen of rivieren zoeken, haar wezenlijk bestaan berust alleen op wel beraisonneerde en dies conform voldane eischen, zoo van Indische produkten als Europesche waren die naar Indië jaarlijks verzonden worden.

7. Palembang, al waar den vorst bij continuatie zeer insteerd op de verstrekking van kruid en lood, voldoet niet aan zijnẹ contracten.

Een millioen pond peper.

Vier millioen pond tin.

Hoe zeer de contracten van een gelijkstandige quantiteit spreken en de Maatschappij met het tin als overkropt raakt en naauwelijks uitweg weet; hoezeer China tot de verglazing van het porcelein en tot hunne afgodendienst, de Maatschappij van een ruime quantiteit ontlast. 
8. Jambij, tegenwoordig van te weinig consideratie; de Vorst zeer kregelig, de peper inzaam tot niet geloopen.

9. Siam, alwaar nog onlangs Compagnies bediendens ten meesten deele zijn gemassacreerd en de goederen gespolieerd, staat finaal geabandonneerd te worden.

10. Japan. Alwaar de Compagnie gezeten is op het eiland Decima, leverd geen onvoordeeligen handel uit, echter bepaald; wijl de Japander niet meer dan twee schepen jaarlijks ten handel admitteerd, waarmede weder naar Batavia zijn overgemaakt de ordinaire 11,000 kistjes Japans staafkoper, dat in India groote winsten afwerpt.

11. China. Welkers vaart en handel nu direct van hier gedreven werd, is op zeer goeden en voordeeligen voet; hoezeer de vaart over Batavia almede hare voorstanders vindt, en nog telkens door Gouverneur en Raden als proferabelder werd voorgesteld, daar men het hier in een ander daglicht beschouwd.

11. Malakka. Alwaar de rust zeer zelden van langen duur is, heeft eindelijk dien blijden dag zien verschijnen, dat eene Radja Mohamet - die sedert eenigen tijd veel spels had berokkend - is uitgeroeid en van hem veroverd zijn 103 stukken kanon; een overwinning die niet zonder bloedstorting en tegenstand is verworven, en waarin Compagnies bodem Pasgeld met 109 schoten is doornageld geworden.

$\mathrm{Na}$ het houden van een plegtigen dank- en bededag over deze heerlijke overwinning en daaruit herborene rust, is dit conquest immediatelijk van beter aanschouw geworden en de lasten merkelijk verminderd.

12. Sumatra's Westkust. Weleer niet onvoordeelig is thans als een kanker in de boezem der Compagnie aan te merken, doch echter om dergevolgen wille niet te abandonneren.

Het goud, kampher en benzoï is kwalijk meer te erlangen.

De districten van Natal en Tappianoelij, worden de Compagnie misgunt en men tracht die twee plaatsen de Compe. te ontrukken, dezelve hebben van langen tijd behoord onder de Maatschappij, doch eenige weinige jaren geleden geinvadeerd en door overmagt de Compagnie onthouden, niet tegenstaande hare gedane representatiën en remonstrantiën.

Doch in Februarij 1760, zijn die twee plaatsen door het regt des oorlogs den possesseur ontrukt en door den overwinnaar overgegeven aan de wettige regenten van het land, die dezelve

VI. (X.) 
weder hebben opgedragen aan de Nederlandsche Maatschappij als aan haren ouden schuts- en schermheer.

$\mathrm{Op}$ beide die plaatsen heeft de Nederlandsche Maatschappij eenige weinige militairen, van welkers noodlot zoo mede van den ganschen toestand van zaken alhier, men nadere informatiën uit India te gemoet ziet, met het schip de Imagonda, dat van Batavia in Texel is aangeland.

14. Bengalen. Tegenwoordig niet zonder aandoening te noemen, verslind schatten zonder vrugt, zoogenaamde liberale giften van 7 à 8 ton, de Maatschappij met de degen op de borst afgeperst, strekken daarvan ten voorbeeld. De lasten van een jaar geklommen zijnde tot boven de 18 ton, zijn niet te vinden uit den verkoop der Bengaalsche produkten, vooral wijl de Compagnie thans qualijk twee scheepladingen kan bekomen, daar zij er aan 4 à 5 gewend is, om de lasten goed te maken. Met den inzaam van lijnwaden, salpeter, amphioen, gaat het van kwaad tot erger en kan de Maatschappij het op dien voet bij continuatie in Bengalen niet houden, te meer daar haar de handen gebonden worden, om den stoutmoedigen Inlander te beteugelen, waarvan geen ander effect kan wezen, als dat de eene Compagnie voor en de andere na uit Bengalen staat verdreven te worden.

15. Chormandel om zijn lijnwaden bekend en beroemd, heeft een vrij favorabele inzaam van 300 pakken vitgeleverd. De inkoop van de produkten des lands heeft bedragen meer dan 15 ton gouds, die zoo hier te lande als in Indië voldoende winsten hebben afgeworpen.

16. Ceilon. Dat dierbaar kleinood van Compagnies bezittingen, daar de Compe. zich door haar eertijds gedugte wapenen, den eigendom der stranden heeft geacquireerd, blijft bij continuatie zeer geallarmeerd en verkeert in factieuse omstandigheden, zoo onder violente opstand onder de Candianen, als om den oorlog met den magtigen Keizer van Candia, welk een en ander waarschijnlijk lang gedempt zou wezen, zoo niet gedurige oprokkeningen en onderstand de muitelingen kwamen te stijven. Oprokkingen en onderstand, die te minder dragelijk zijn, omdat dezelve volgen op meenigvuldige geriefelijkheden Compagnies-wegen bewezen aan talrijke vloten, die zoo van den een als van den ander te Triconomale maanden lang hebben vertoefd, en vandaar middel hebben weten te vinden om den Keizer op te rokkenen tegen de Nederlandsche Maatschappij, 
onder representatie dat de zoogenaamde strandbewoners wel te verdrijven zouden wezen.

Het is ook in zoo verre de Candianen gelukt, dat zij zich van een zeeplaats Mature-hebben meester gemaakt, doch daaruit verdreven zijnde, zoo heeft men van haar veroverd 15 stukken geschut, waaronder een Engelsche twaalfponder.

In deze onlusten is de inzaam der produkten vrij favorabel, en zijn nog onlangs vier schepen van daar geretourneerd met meer dan dertien tonnen gouds inkoops. Het goed beleid en de ervarenheid van den tegenwoordigen Ceilonschen Gouverneur Van Ek, geeft hoop dat de rust spoedig zal geboren worden; hij treed in de voeten van zijn voorganger Schreuder en heeft met zich van Chormandel gevoerd meer dan 1000 Sipay's of Inlandsche soldaten, van welke men echter zoo veel dienst niet heeft als van Europesche manschap.

Het is als een zeer zware slag aan te merken, dat het van Batavia herwaards geschikte renfort voor het grootste gedeelte haar graf heeft gevonden in de Ceylonsche baren en dat wel door een orkaan, die in Maart 1762 alhier heeft gewoed en drie à vier schepen van de Compe. heeft verslonden, tot welkers remplacement, voornamelijk van verlorene manschap, de noodige mesures zijn genomen.

17. Malabaar. Heeft $1.700,000$ pond peper geleverd, de Koning van Travancore blijft bij continuatie zeer gedugt, niet alleen onder de Inlandsche Vorsten, maar hij makt zich zelven redoutabel bij de Compe.

18. Souratte. Is den handel vrij wel geslaagd, als afgeworpen hebbende bijna 6 ton aan winst; de Bond- en geloofsgenooten zijn hier vrij wel.

19. Kareck. Een eiland in de Persische golf is thans het eenigste etablissement van dien aard, nog onlangs (is) daarvan een ophef gemaakt, even als of alle de Nederlandsche fabrieken kwalijk in staat zouden wezen om genoegzame manufacturen, speciaal die van lakenen te kunnen aanmaken. Doch die groote ophef is in ijdele rook verdreven, en staat het werk hier gedisponneerd om dit etablissement geheel en al te quitteeren, hoezeer aldaar een fort Mosselstein is geïnstitueerd, dat meer dan $f 100,000$ heeft gekost.

20. Batavia en de onderhoorige kantoren.

Java's Oostkust, thans in volle rust, mild in produkten; 15 millioen ponden rijst. 
Cheribon ingezameld 15maal honderd duizend ponden koffijboonen en de andere produkten van suiker, peper, curcuma, indigo en katoenen garens, mede voldoende.

Een gezegend land, zoo als speciaal de van daar retournerende Residenten getuigen, die bovendien van dien zegen zulke zichtbare blijken geven, dat het een ieder doet watertanden, om voor een korten tijd dat residentschap te bekleeden. Men is bij de Compe. bedagt op middelen om de intrinsicque gesteldheid van de huishouding aldaar na te gaan, en de Compe. mededeelgenoot te maken van dien milden zegen.

Bantam in twaalf maanden meer dan twee millioen ponden peper uitgeleverd.

Te Batavia is het eenige tijd zorgelijk gesteld geweest, zoo door bedreiging als door dadelijkheden, schending van Compe. vlag, aanranding harer bodems en wat dies meer (zij). De zorgelijke omstandigheden hebben den tegenwoordigen Gouverneur-Generaal van den Parra doen aarzelen, alvorens hij het Generalaat heeft aanvaard, doch zich tot dies acceptatie verpligt oordeelende, zoo is hij daarin geconfirmeerd; zoo •als mede Mr. Librecht Horeman in het zwaarwigtig ambt van Directeur-Generaal, en is wijders de noodige voorziening zoo omtrent de Hooge Regering als Raad van Justitie gedaan.

21. De Kaap heeft sedert eenigen tijd verstrekt voor vreemde schepen voor een magazijn van geriefelijkheden, aan - alle natiën bewezen, daar zij zelfs zeevarend volk hebben erlangd, om hunne schepen door zee te brengen.

De produkten des lands zijn daardoor zeer in prijs gesteigerd, waarin de Compe. mede heeft moeten dragen, en dus ter harer kosten medehelpen contribueren tot florisance van de Colonie.

Compagnies Etablissementen dus kortelijk doorloopen zijnde, bevinden zich de zaken hier te lande genoegzaam in dezelfde termen, als die bij het laatste gedane rapport zijn voorgesteld.

Sedert geëntameerd zijnde de onderhandelingen te Londen, is aan het oogmerk van deze commissie tot nog toe in geenderlei opzigten voldaan. Op geen één punt heeft de Maatschappij genoegen kunnen bekomen en het $4^{\mathrm{e}}$ punt, sprekende van de voorziening voor het toekomende, is nog onaangeroerd. Ondertusschen levert het verblijf van commissarissen te Londen, een zeer merkelijk bezwaar uit voor Compe.-kas en is thans zeer noodeloos, ja! in die termen dat met permissie van Uwe Hoog-Mogenden, de tehuiskomst het raadzaamste was. 
Uit dit geavanceerde op verscheiden respecten blijkt, hoe zorgelijk de zaken in India, hoe onvoordeelig elders staan.

Slot. Bewindhebberen vinden zich dus te meer verpligt om met allen nadruk - edoch verschuldigde eerbiedigheid - te imploreren het appui en de magtigen arm van Uwe Hoog-Mogenden, en een Maatschappij moge worden gemaintineerd en des mogelijk staande gehouden, wiens val, ja reeds verval voor zoo nadeelig gehouden moet worden.

Wensch. Bewindhebberen besluiten dit hun Rapport met een wensch en bede tot God, dat alle de deliberatiën en besluiten van Uwe Hoog-Mogenden, zoo over het algemeen welzijn, als over de Maatschappij, met een gewenscht einde moge worden bekroond en dat Zijn dierbare gunst (van) Uwe Hoog-Mogende Illustre persoonen, derzelver famillie en regering moge afweren al wat aan derzelver genoegen en geluk hinderlijk en aan het algemeen belang eenigzins nadeelig zoude kunnen zijn.

$\mathrm{Na}$ het eindigen van dezen wensch, reed de Commissie in dezelfde order zooals zij naar de vergadering was gereden, naar het Logement terug, waar des middags een maaltijd plaats had, waaraan de volgende personen deel namen, als:

de Heeren de Wilhem Bewindhebberen Kamer Amsterdam.

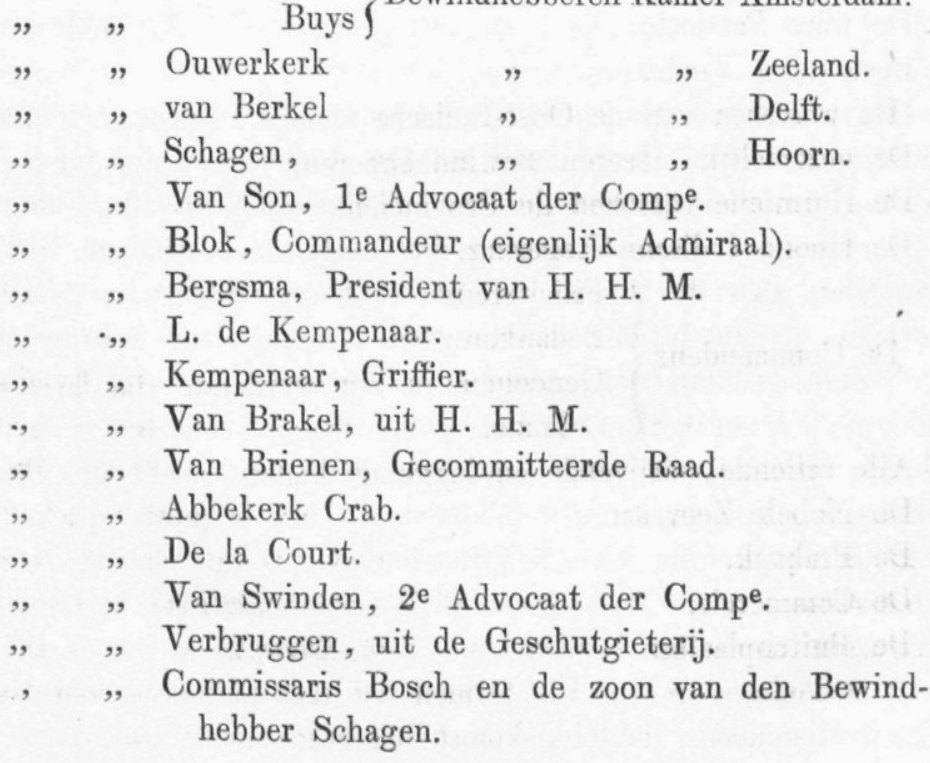


Voorts waren nog genoodigd, doch niet verschenen de Heeren : de Raadpensionaris Stein.

„, Griffier Fagel.

„, Essayeur Emants (als vriend van Blok).

"Advocaat B Brouwer.

Rijgerbosch.

van der Streng.

„, Procureur van Mezel.

"Agent Horeman.

„, Bewindhebber Vaillant.

Uit H. H. Mog. Woestman.

", Agent Bymont.

„Raadsheer Meerens, en

den gewezen Bewindh. Boetselaar.

De gezondheden bij deze gelegenheid gedronken - ieder zijn regterhand om - waren de volgende:

De Dames.

De Inclinatiën.

De Familiën en wat dies meer.

Hun Hoog-Mogenden.

Het welvaren van deze Provinciën.

Zijne Hoogheid.

Het Vorstelijk Huis.

Alle welmeenenden.

De ware Patriotten.

Bestendige Vrede.

Het welvaren van de Oost-Indische Compe

De gezamelijke Heeren Bewindhebberen.

De Harmonie tusschen de Provinciën.

De Hooge Indische Regering.

De Commandeur $\left\{\begin{array}{l}\text { Filiciteren. } \\ \text { Bedanken. } \\ \text { Genoegen in zijn verderen tijd hier te } \\ \text { lande. }\end{array}\right.$

Alle zeilende, drijvende en leggende kielen.

De Nobele Zeevaart.

De Praktijk.

De Commercie.

De Buitenplaatsen. 
EXTRACT UIT 'T REGISTER DER RESOLUTIËN VAN DE HOG. MOG. HEEREN STATEN-GENERAAL DER VEREENIGDE NEDERLANDEN.

Mercuri, den 20sten April 1763.

De Gecommitteerdens van de Bewindhebberen van de Generale Geoctroyeerde Oost-Indische Compe. dezer landen, met de Advocaat van dezelve Compe., Mr. Augustinus van Son, ter vergadering gecompareert zijnde, hebben aan Haar Hoog-Mog. gepresenteert den Persoon van Roelof Blok, als Commandeur van de Retourvloot van Batavia, vertrokken den laasten October $1761^{1}$ en den $2^{\text {den }}$ Junij 1762 hier te lande gearriveerd; dewelke rapport heeft gedaan van hetgeen op de reijse van gemelde Retourvloot is voorgevallen en heeft daarnevens overgeleverd zijn schriftelijk Rapport. Vervolgens heeft den Advocaat van Son aan Haar Hoog-Mogende ook een omstandig verhaal gedaan van den toestand van zaken in Indiën, waarop gedelibereerd zijnde, is goedgevonden en verstaan, dat het voorsz. schriftelijk Rapport van den gemelden Commandeur ter griffie zal worden gedeponeerd om te zijner tijd te dienen, zulks en daar het behoord.

$$
\text { (get.) J. BERGSMA. }
$$

Accordeert met het voorsz. dagregister.

$$
\text { (get.) H. FAGEL. }
$$

12 November 1761. 